\title{
Ischemic cardiomyopathy: A review of literature on clinical status and meta-analysis of diagnostic and clinical management
}

\author{
Aref Albakri* \\ St-Marien hospital Bonn Venusberg, Department of Internal Medicine, Bonn, Germany
}

\begin{abstract}
Ischemic heart disease is the leading cause of sudden cardiac death. It may lead to cardiomyopathy in the setting of coronary artery disease and gradually progressing to heart failure. While ischemic cardiomyopathy is a well-recognized disease entity, the current classification systems of cardiomyopathy exclude cardiomyopathies secondary to ischemia. Further, research on ischemic cardiomyopathy is extensively fragmented, which has undermined both research consensus and comprehensive understanding. The fragmentation is attributable to its variable terminologies (ischemic heart disease or its three leading non-fatal sequela - angina pectoris, acute myocardial infarction and ischemic heart failure). Therefore, the purpose of the present review is to accumulate research on ischemic cardiomyopathy to produce a comprehensive understanding of its clinical status, diagnosis, clinical management and improve survival.
\end{abstract}

\section{Introduction}

Ischemic cardiomyopathy (ICM) is an important etiology of heart failure. Despite significant advances in clinical management, heart failure due to ICM continues to have high mortality rates. With limited availability of chronic treatment options such as heart transplantation, accurate prognostication remains an important therapeutic goal, especially in the understanding of the physiopathology of the left ventricular (LV) remodeling in the early stages of ICM, which should convey a protective effect against progressive development of heart failure. This paper reviews scholarly and practitioner literature on ICM, with a focus on description, global burden, clinical presentation, prognosis, etiopathogenesis, diagnosis and clinical management [1-7].

\section{Historical and clinical description}

\section{Clinical description}

Clinical definition of ICM has been inconsistent. Early definitions were pathologic-based, described as an anatomic cardiac condition originating from sustained imbalance between cardiac oxygen supply and demand resulting into myocyte loss, myocardial scarring and ventricular failure [8]. Another early definition suggest ICM is myocardial infarction, angina pectoris and abnormal echocardiographic findings in response to standard exercise or death due to arteriosclerotic heart disease or sudden death unexplained by other demonstrable cardiac causes [9]. A recent clinical definition based on LV dysfunction provided by the large-scale Surgical Treatment for Ischemic Heart Failure (STICH) trial defines ICM as a severe reduction of LV function $<35 \%[9,10]$ or $<50 \%[11]$ in the presence of severe CAD. However, Felker et al. [7] developed the current widely accepted standardized definition of ICM adopted by the Duke Databank and widely used in clinical practice in the U.S, U.K and Europe. They based the definition on prognostic evaluation of the association between the degree of CAD and survival in 1,921 patients recruited between 1986 and 1999 presenting with symptomatic heart failure (HF) and ejection fraction $\leq 40 \%$. They defined ICM as patients with: a) A history of myocardial infarction (MI) or revascularization by coronary artery bypass grafting $(\mathrm{CABG})$ or percutaneous coronary intervention (PCI).

b) With $\geq 75 \%$ stenosis of left main or proximal left anterior descending coronary artery without a history of $\mathrm{MI}$ or prior revascularization

c) With $\geq 75 \%$ stenosis of $\geq 2$ epicardial vessels

Based on the current definitions of ICM, the dominant morphological characteristic are ventricular dilation and depressed myocardial contractility, which mimics non-ischemic DCM. However, ICM is a distinct clinical entity from DCM based on the observation that its predominant etiology is abnormal loading conditions such as hypertension, valvular disease or CAD in sufficient quantities to cause global systolic dysfunction [12].

\section{Global burden}

The lack of dedicated population-based epidemiology studies on ICM as a distinct clinical entity has undermined the precise knowledge of its prevalence and incidence. However, due to different terminologies and the exclusion of ICM in the current classification systems of cardiomyopathies, most studies on incidence and prevalence of ICM refer to the disorder as ischemic heart disease or its three leading nonfatal sequela: angina pectoris (AP), acute myocardial infarction (AMI) and ischemic heart failure (IHD) [13-16]. Further, a majority of studies on ICM investigate its global burden defined as death from IHD and years of living with disability due to non-fatal sequela (AP and AMI).

${ }^{\star}$ Correspondence to: Aref Albakri, St-Marien hospital Bonn Venusberg, department of internal medicine, Bonn, Germany, E-mail: arefalbakri@yahoo.com

Key words: angina pectoris, ischemic cardiomyopathy, ischemic heart disease, ischemic heart failure, myocardial infarction

Received: September 21, 2018; Accepted: October 04, 2018; Published: October 08,2018 
The global incidence and prevalence of non-fatal sequela of ICM vary based on the findings of the Global Burden of Disease 2010 Study conducted between 1990 and 2010 [14] (Table 1).

The Global Burden of Disease 2010 Study [14] further reports the average age of first incidence of AMI and AP ranges between $>70$ and $>60$ years in high incomes regions and $<65$ and $<55$ years in low and middle-income regions (South Asia, North Africa/Middle East, and the sub-Saharan Africa). Between 1990 and 2010, years lived with ICM-related disability increased by $15 \%$ to $33 \%$ in high-income regions and $13 \%$ to $100 \%$ in low and middle-income regions [14]. The findings suggest that the incidence and prevalence of ICM varies globally based on regions, socio-economic conditions and the extent of the development in healthcare system.

\section{Causes and risk factors}

The principal cause of ICM is coronary artery disease or heart attack. Coronary artery disease narrows coronary luminal size restricting coronary perfusion relative to myocardial demand for oxygenated blood [8]. Several risk factors have been proposed predisposing individual to the development of coronary artery disease and subsequently ICM.

\section{Risk factors}

It is axiomatic in the effective control of ICM that the initial step is risk stratification for the identification of individuals at low and high risk of developing the cardiac condition. The clinical objective is to identify characteristics of the two groups (low- and high-risk) to inform prompt institution of the most appropriate available prophylactic, palliative, therapeutic or curative clinical interventions [17,18]. Risk factors for the development of ICM also includes those supporting the development of coronary atherosclerosis, which is the principal etiopathogenic substrate of ICM [18]. Thus, ICM shares the same risk factors as coronary artery disease, which include diabetes, hypertension, smoking, poor nutrition, sedentarism, obesity, dyslipidemia, male gender, advancing age and family history of IHD [17,18,19].

\section{Major longitudinal studies on risk factors}

Two early longitudinal studies - the Cardiovascular Health Center (CVHC) at Albany and the Public Health Service Project at Framingham Mass report that environmental factors such as poor nutrition, the lack of physical exercise (sedentary lifestyle), chronic use of tobacco and obesity are independent risk factors for developing ICM. Other common risk factors are biological such as old age, the male gender, serum lipids (especially cholesterol) and obesity [17]. The Caerphilly and Speedwell Collaborative Heart-Disease studies recruiting a cohort of 4,860 middle-aged men between 1979 and 1983 find smoking is an independent risk factor for the development of ICM but mediated by hemostatic or rheological factors such as fibrinogen, viscosity, and white blood cell count $[18,19]$.

Table 1. Global Incidence and Life with Disability of ICM Non-Fatal Sequela [14]

\begin{tabular}{|l|c|c|c|c|}
\hline Disorder: ICM Non-Fatal Sequela & \multicolumn{2}{|c|}{1990} & \multicolumn{2}{c|}{2010} \\
\hline & Males & Females & Male & Females \\
\hline Acute Myocardial Infarction (Incidence/100,000) & 222.7 & 136.3 & 195.3 & 115.0 \\
\hline Angina Pectoris (Prevalence/100,000) & 21.9 & 17.7 & 20.3 & 15.9 \\
\hline Ischemic Heart Failure (Prevalence/100,000) & 2.4 & 1.9 & 2.7 & 1.9 \\
\hline
\end{tabular}

Adapted from Global Burden of Disease 2010 Study 1990-2010 [14]

\section{Clinical symptoms and presentation}

Signs and Symptoms: Ischemic cardiomyopathy is an important cause of heart failure in middle-aged and geriatric populations. Thus, important clinical signs of ICM is a history of heart attack and angina pectoris. Patients may also present with symptoms of heart failure, which usually progress very slowly over a long period [20]. The most frequently encountered clinical symptoms of ICM include exertional dyspnea (shortness of breath when under intense physical activity), peripheral edema, fatigue and tiredness, persistent coughing, pulmonary congestion, palpitations or fluttering due to arrhythmias, dizziness, weight gain and loss of appetite [20,21]. These clinical signs and symptoms should prompt for further diagnostic evaluation for ICM or any other suspected etiology for heart failure.

\section{Clinical presentation}

Clinical presentation of ICM usually range from stable chronic angina to sudden cardiac death [22]. The clinical spectrum includes three leading sequelae of ICM: angina pectoris, acute myocardial infarction with or without ST segment elevation and unstable angina usually catalogued as acute coronary syndrome and ischemic heart failure all occurring secondary to myocardial ischemia (an imbalance between perfusion and cardiac demand for oxygenated blood) [22,23]. In a greater majority of cases (90\%), myocardial ischemia results from the obstruction of coronary circulation by atherosclerotic plaque and thus ICM may also be referred to as coronary heart disease or coronary artery disease $[9,10,11,24]$. Mostly, ICM has a slow progression from asymptomatic coronary atherosclerotic obstruction, which may last for decades. Clinical presentation of ICM may be classified into four sequela (acute coronary syndromes).

\section{Angina pectoris}

Angina pectoris (AP) defined as chest pain due to myocardial ischemia, presents as a tight, squeezing pain, like a weight on the chest and accounts for up to $50 \%$ of clinical diagnosis of ICM [25]. Chest pain may also be due to non-cardiac conditions or sources such as muscoloskeletal or gastroesophageal disorders, which presents with distinct description, site of pain and precipitants of pain. Angina pectoris (cardiac pain) has distinguishable characteristics from noncardiac chest pain [25] (Table 2).

Angina pectoris has the clinical characteristics of paroxysmal and recurrent attacks of substernal or precordial chest discomfort secondary to transient ( 15 seconds to 15 minutes) myocardial ischemia that is insufficient to lead to myocyte necrosis that defines myocardial infarction. Angina pectoris has three overlapping patterns in ICM: (a) stable or typical angina pectoris; (b) variant or Prinzmetal angina; (c) unstable or crescendo angina. These patterns are due to elevated myocardial demand and/or reduced myocardial perfusion secondary to fixed or disrupted atherosclerotic plaques, vasospasm, thrombosis or embolization [25] (Table 3).

\section{Myocardial infarction}

Myocardial infarction, also known as heart attack, and defined as myocardial death due to ischemia, is the most deleterious clinical presentation of ICM and a leading case of ICM-related death in industrialized nations [26]. Approximately 50-70\% of ICM patients, acute MI is the initial clinical manifestation [25]. Myocardial infarction may clinically present as transmural or sub-endocardial. Transmural MI is the most common, marked with ischemic myocyte necrosis of nearly or entirely the thickness of ventricular wall in a single coronary 
Table 2. Differences between Angina Pectoris and Non-Cardiac Chest Pain [25]

\begin{tabular}{|l|l|l|}
\hline Description & $\begin{array}{l}\text { Angina Pectoris } \\
\text { (Cardiac Pain) }\end{array}$ & $\begin{array}{l}\text { Extra-cardiac Pain (Muscoloskeletal } \\
\text { or Gastro-esophageal }\end{array}$ \\
\hline Description of Pain & $\begin{array}{l}\text { Heavy, tight, pressure, dull, } \\
\text { band or squeezing }\end{array}$ & $\begin{array}{l}\text { Sharp, stabbing, shooting or needle } \\
\text { like }\end{array}$ \\
\hline Site of Pain & Central anterior & Left sub-mammary \\
\hline & $\begin{array}{l}\text { Left arm, right arm, teeth, } \\
\text { inter-scapular or epigastric }\end{array}$ & Right sub-mammary \\
\hline \multirow{2}{*}{ Precipitants of Pain } & Exercise or emotion & Stress \\
\cline { 2 - 3 } & Cold & Locally tender \\
\cline { 2 - 4 } & Post-prandial & $\begin{array}{l}\text { Body posture (sitting/standing), arm } \\
\text { movements or odynophagia (pain } \\
\text { due to neck swallowing) }\end{array}$ \\
\hline
\end{tabular}

Table 3. Three Patterns of Angina Pectoris and their Clinical Description [25]

\begin{tabular}{|l|l|}
\hline Anginal Pattern & Clinical Description of Angina Pectoris (AP) Pattern \\
\hline Stable/Typical & $\begin{array}{l}\text { It is the most common AP pattern caused by restricted coronary } \\
\text { perfusion resulting from coronary atherosclerosis, which } \\
\text { predisposes the heart to increased ischemia when there is increase } \\
\text { demand for oxygenated demand during precipitation factors } \\
\text { such as exertion, emotional excitement or extreme temperatures } \\
\text { that increases cardiac workload. Stable AP is relieved by rest } \\
\text { or sublingual nitrates (such as nitroglycerin), which is a strong } \\
\text { vasodilator of peripheral vasculature. }\end{array}$ \\
\hline Variant/Prinzmetal & $\begin{array}{l}\text { An uncommon pattern of episodic AP occurring at rest usually } \\
\text { resulting from coronary artery spasm. The pattern is characterized } \\
\text { by electrocardiogram (ECG) elevated ST segment indicating } \\
\text { transmural ischemia. Individuals have significant coronary } \\
\text { atherosclerosis but anginal attacks are unrelated with exertion, } \\
\text { heart rate or blood pressure. This AP pattern does respond to } \\
\text { vasodilators (nitroglycerin) and calcium channel blockers. }\end{array}$ \\
\hline Unstable/Crescendo & $\begin{array}{l}\text { AP pattern occurring with progressively increasing frequency of } \\
\text { pain with progressively less effort, often occurring at rest with } \\
\text { more prolonged duration. It is due to atherosclerosis with mural } \\
\text { thrombosis and embolization, vasospasm or both. Although } \\
\text { ischemia related to unstable AP is close to induce clinically } \\
\text { demonstrable infarction, it is a prodrome to acute myocardial } \\
\text { infarction and at times known as pre-infarction angina lying } \\
\text { between stable angina and myocardial infarction. }\end{array}$ \\
\hline
\end{tabular}

artery. It is associated with atherosclerotic plaque, acute plaque change or superimposed thrombosis. Contrastingly, sub-endocardial MI constitutes myocyte necrosis of one third to one-half of the ventricular wall but may extend beyond the perfusion of a single coronary artery. It results from plaque disruption followed by thrombosis prior to myocyte necrosis extending to the thickness of the ventricular wall or from prolonged and severe reduction of systemic blood pressure [25].

\section{Ischemic heart failure}

Chronic ischemic heart failure defines a cardiac syndrome developing due to progressive heart disease in the setting of ischemic myocardial damage. Patients diagnosed with ischemic heart failure usually have prior myocardial infarction and coronary artery bypass graft (CABG) surgery or other therapeutic interventions [27]. Ischemic heart failure presents with post-infarction cardiac decompensation resulting from the exhaustion of compensatory hypertrophy of noninfarcted myocardium, which is also at risk of ischemic injury. In some cases, patients with ischemic heart failure may present with severe coronary artery disease in the absence of acute or healed infarction but in the presence of diffuse myocardial dysfunction [26].

Although diagnosis is based largely on insidious onset of congestive heart failure in patients with previous episodes of myocardial infarction or angina. In some patients, progressive myocardial damage may be asymptomatic and heart failure is often always the first clinical manifestation of ischemic heart disease, and diagnosis is usually by exclusion of other etiologies of cardiac causes [22]. Clinical manifestations of ischemic heart failure include cardiomegaly, described as enlarged and heavy heart due to left ventricular hypertrophy and dilation. Patients present with moderate to severe coronary artery atherosclerosis or complete blockage with discrete gray scars indicating healing infarcts [26].

\section{Sudden cardiac death}

Sudden cardiac death (SCD) defined as unexpected death due to cardiac causes within an hour after the onset of symptoms (or in the absence of symptoms) may occur as the first and only clinical manifestation of ischemic cardiomyopathy [28]. It occurs secondary to myocardial infarction and/or ventricular arrhythmias [29]. The lack of premonitory symptoms for SCD undermines effective clinical management for ICM patients and underscores the need for a population-based primary prevention approach. Population-based markers such as a family history of SCD is important as is the exclusion of other causes such as cardiomyopathies, long QT syndromes or cerebrovascular aneurysms and malformations [28].

\section{Prognosis}

\section{Clinical importance}

Heart failure is one of the most devastating clinical outcomes for ICM patients. Heart transplantation remains the mainstay chronic treatment conveying protective effect against cardiac death and improving survival rates in end stage ICM. Thus, predicting prognostic factors is important to elect patients for heart transplantation because of its limited availability [7]. The etiology of LV dysfunction is an important prognostic factor for the development of heart failure or the efficacy of treatment. This is evident in an increase in studies demonstrating a shift from hypertension and valvular disease to ischemia as the most important cause of heart failure in the U.S. in the past few decades [30]. Heart failure secondary to ischemic heart disease has an independent effect on long-term unfavorable prognosis for patients with severe LV dysfunction [31-34]. Knowledge of the etiology of heart failure is also significant in the decision to consider revascularization and understand the effect of pharmacological therapy for patients with ischemic heart disease. It may also provide valuable information in the differential diagnosis of ischemic and nonischemic heart diseases demonstrated to have different pathological mechanisms for sudden cardiac death in the Assessment of Treatment with Lisinopril And Survival (ATLAS) trial [35].

\section{Historical context}

Ischemic cardiomyopathy (ICM) is a relatively recent classification of cardiomyopathy. Since the initial description of cardiomyopathy in 1957 by Brigden [1], classification systems have excluded cardiomyopathies secondary to cardiac ischemia as a distinct form of cardiomyopathy. The initial classification system by the World Health Organization (WHO) and the International Society and Federation of Cardiology (ISFC) task force in 1981 only identified and listed three clinically distinct phenotypes of cardiomyopathies: dilated cardiomyopathy (DCM), hypertrophic cardiomyopathy (HCM) and restrictive cardiomyopathy (RCM) [2]. In the subsequent 1996 WHO/ISFC revision, the task force added arrhythmogenic right ventricular dysplasia (ARVD) as the fourth clinically distinct form of cardiomyopathy [3].

Despite the exclusion, the initial clinical mention of ischemic cardiomyopathy dates back to 1969 , described by Raftery and associates 
[4] as global left ventricular (LV) dysfunction in the setting of coronary artery disease (CAD). The study reported a causal relationship between CAD and congestive cardiomyopathy [5]. A year later in 1970, Burch and associates [6] originated and popularized the term "ischemic cardiomyopathy". The term was meant to propose an alternative etiology-based classification system to the current descriptive one to help distinguish between ischemic and non-ischemic cardiomyopathies that have clinically distinct prognosis. They associated ischemic heart failure with a shorter survival rate compared to heart failure due to nonischemic cardiomyopathies [6]. Three decades later in 2002, the Duke Databank validated the term ischemic cardiomyopathy by developing a standardized clinicopathologic definition [7].

\section{Prognostic factors}

Chronic ischemic cardiomyopathy has poor prognosis with significant morbidity, reported at $19 \%$ in patients having a moderately to severely decreased systolic-function (ejection fraction $\leq 35 \%$ ) within 22 -months follow up [36]. The age of the patient, capacity to exercise and the presence of comorbidities frequently predict survival rates. However, the most important prognostic factors in ICM patients usually determined using gated Single-Photon Emission Computed Tomography (SPECT) are the degree of myocardial ischemic damage, myocardial viability and left ventricular remodeling $[37,38]$. Contractile dysfunction resulting from myocyte necrosis also known as viable myocardium may also indicate worsening prognosis. Viable myocardium is defined as a living myocardium characterized by severe abnormal contractility indicating myocardial stunning due to transitory ischemic episode/reperfusion with spontaneous reversal or myocardial hibernation occurring in the context of chronic ischemic disease requiring revascularization to recover LV function [38].

\section{Etiopathogenesis}

The principal etiopathogenic mechanism for the development of ICM is an imbalance between coronary perfusion and myocardial demand for oxygenated blood. The imbalance results from a complex and dynamic interaction between stenosing atherosclerotic plaque narrowing epicardial coronary arteries, intraluminal thrombosis due to lysing atherosclerotic plaque, platelet aggregation and vasospasm [8]. Acute changes in atherosclerotic plaque, inflammation, coronary thrombus and vasoconstriction all play important roles in the pathophysiology of atherosclerotic plaque as discussed below.

\section{Role of acute plaque change}

Abrupt changes in coronary atherosclerotic plaques followed by thrombosis have been associated with myocardial ischemia, unstable angina, acute myocardial infarction and sudden cardiac death in patients with ICM [39]. These pathological changes, known as acute coronary syndromes, results from disruption of stenosing atherosclerotic plaque with one of the following characteristics.

a) Lysing exposing thrombogenic plaque constituents;

b) Ulceration exposing thrombogenic sub-endothelial basement membrane to blood; and

c) Hemorrhage into atheroma expanding its volume [40].

The progression of coronary atherosclerosis lysing, starting from fixed chronic atherosclerotic plaque causing angina progressing into plaque disruption and platelet aggregation and ultimately acute coronary syndrome (Figure 1).
The events triggering acute changes in plaque are incompletely understood but it is proposed that intrinsic factors such as plaque structure and composition, and extrinsic factors such as blood pressure and reactivity of plaque play a significant role $[38,39]$.

\section{Role of inflammation}

Inflammation plays significant pathologic roles in all stages of pathogenesis of atherosclerosis, beginning right at its initiation to the development of associated complications [38]. The onset of coronary lesion occurs within the context of the interaction between endothelial cells and circulating leukocytes, which precede deposition of T cells and macrophages on the wall of coronary artery. Secretion of chemokines by endothelial cells and their increased expression of adhesion proteins (in the endothelial cells) lead to the entry of leukocytes into coronary artery wall. $\mathrm{T}$ cells on the coronary artery wall release cytokines stimulating endothelial cells and activate macrophages loaded with oxidized LDL. As atherosclerosis progresses, destabilization and lysing of plaque involves macrophages producing the enzyme metalloproteinase, which destabilizes the plaque by digesting collagen at the fibrous cap or at the shoulder of the lesion [40]. Due to the importance of inflammation in atherosclerosis, several of the involved inflammatory proteins especially hepatic C-reactive protein served as important risk markers for atherosclerosis and coronary heart disease. These proteins could also serves as predictors of the risk of $\mathrm{MI}$ in patients with angina and the risk of recurrence of $\mathrm{MI}$ in surviving patients [38,39].

\section{Role of coronary thrombus}

As illustrated in Figure 1, mural or occlusive thrombosis associated with disrupted atherosclerotic plaque is critical to the pathogenesis of acute coronary syndrome. In acute transmural myocardial infarction, thrombus that is superimposed on disrupted partial stenosing atherosclerosis may convert into total occlusion of coronary artery. On the other hand, unstable angina, acute sub-endocardial infarction or SCD have mural thrombus (incomplete obstruction of the lumen by thrombosis), which may reduce with time [40]. Autopsy findings reveal thrombotic constituents in distal intramyocardial circulation or micro-infarcts in patients who had unstable angina or SCD to suggest that mural thrombus may embolize in a coronary artery. Thrombus may also act as activator of multiple growth-related signals in smooth muscle cells thus contributing to the development of atherosclerotic plaque [8].

\section{Role of vascular remodeling}

Vascular remodeling is the relationship between changes in the volume of coronary atheroma, coronary artery lumen size and the external vessel size. It is critical to the pathophysiology of ICM since it determines the cross-sectional area available for coronary circulation [41-43]. Coronary lumen size depends on atheroma volume (plaque deposition). Plaque deposition occurs mainly within the coronary vascular wall with positive vascular remodeling (compensatory enlargement of outer elastic membrane) to maintain the lumen size $[43,44]$. Compensatory enlargement is more frequent and in greater extent in patients with acute coronary syndrome (ACS) than in those with chronic coronary syndrome (CCS), whose central feature is the loss of compensatory enlargement [45]. Vulnerable plaque is a more critical pathophysiologic factor in ACS while the extent of stenosis is a more critical factor in CCS.

When the compensatory process is exhausted, plaque deposition begins to compromise luminal size decreasing the cross-sectional area available for coronary circulation, a process referred to as negative 


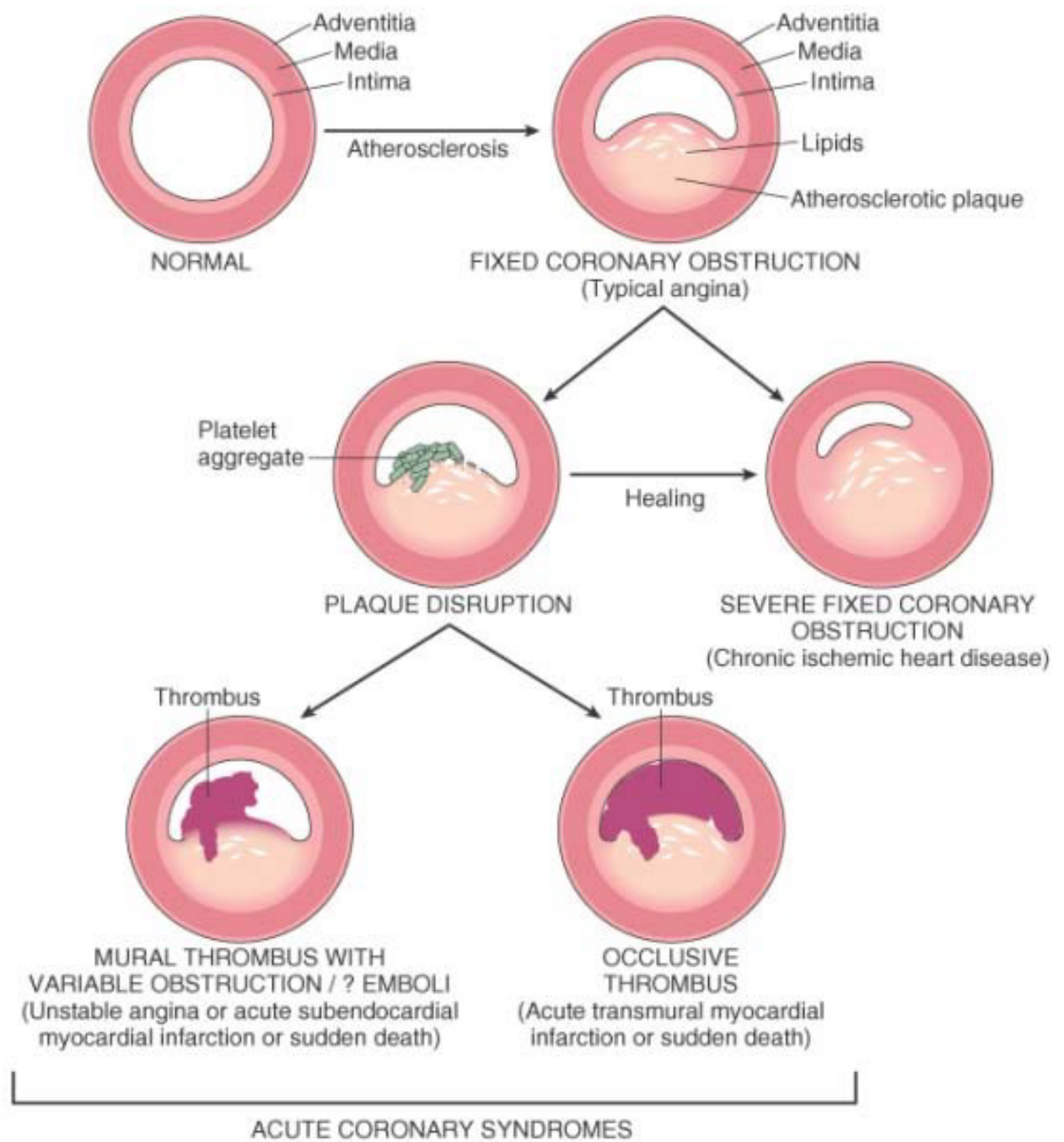

Figure 1. Lysing of Atherosclerotic Plaque in Ischemic Heart Disease [40]

Progression of coronary atherosclerosis lysing, from atherosclerotic plaque (fived coronary obstruction (typical angina), platelet aggregation and distribution to mural thrombus or occlusive thrombus (acute coronary syndrome).

remodeling or loss of compensatory enlargement [40]. The progression of negative remodeling increases the ceiling for coronary perfusion to respond to increased myocardial oxygen demand. Ultimately, increased in plaque deposition and/or negative remodeling narrows coronary luminal size. Narrowing of about $70 \%$ restricts ceiling for increased coronary perfusion relative to increased myocardial oxygen demand leading to ischemia $[45,46]$.

\section{Diagnosis}

Since the primary etiology of ICM is coronary artery disease (CAD) $[6,47,48]$, the basis of diagnosis is usually the detection of coronary stenosis and potentially reversible or hibernating myocardium defined as an improvement in cardiac contraction after revascularization [46]. Diagnosis work-up of ICM consists of clinical evaluation of patients with chest pains and non-invasive diagnostic tests [49].

\section{Clinical evaluation}

\section{Clinical evaluation of patients with chest pains (Angina)}

The 2012 American College of Cardiology Foundation (ACCF)/ American Heart Association (AHA) Task Force on practice guidelines recommends the initial diagnosis of ICM is clinical evaluation of patients presenting with chest pain (angina) [50]. However, angina is not conclusive since it is also present in about $30 \%$ of patients with non-ischemic cardiomyopathy [48]. Patients with chest pains should undergo history and physical examination to evaluate the possibility of ICM or to recommend additional tests. Patients with acute angina should undergo risk stratification and categorization as stable or unstable [50]. Clinical evaluation should consider accompanying signs and symptoms, history, and risk markers to strengthen suspicion for ICM [25].

\section{Physical examination}

Physical examination is usually non-specific for angina but useful for detecting evidence of alternative diagnosis such as heart failure, valvular heart disease, musculoskeletal disorders or hypertrophic cardiomyopathy [51]. Indirect evidence such as severe hyperlipidemia suggests CAD or third heart sound and dependent edema suggests impaired LV function [25]. Elevated blood pressure, xanthomas and retinal residues suggest the presence of ICM risk factors while pain due pressure on the chest wall suggests musculoskeletal causes bur does not exclude the possibility of ICM-associated angina [49]. 


\section{Resting electrocardiogram}

A resting electrocardiogram (ECG) is usually recommended for patients without any clinically demonstrable non-cardiac cause of chest pain [50]. Resting ECG reveals abnormalities suggesting poor prognosis in ICM patients compared to those with normal ECG [5254]. Pathological Q-waves suggesting evidence of prior myocardial infarction [55], persistent ST-T waves inversion, left bundle branch block (LBBB), second or third degree atrioventricular block or left ventricular hypertrophy [56-59].

\section{Chest X-ray}

Chest X-ray is of limited use in the diagnostic work-up of ICM. However, it is useful in providing evidence of alternative pulmonary explanations to signs and symptoms of ICM [49]. It may provide indirect evidence of heart failure. Increased cardiothoracic ratio and pulmonary venous congestion is indicative of heart failure. Although nor reliable, aortic contour may suggest aortic dissection or thoracic aortic aneurysm. Other clues suggesting causes of chest pain may include pleural shadowing, radiographic features of pulmonary hypertension, masses in lungs and fluid level of hiatus hernia [25].

\section{Blood tests}

Blood tests are useful for revealing risk factors for CAD. Full blood count detects anemia (a risk factor), thyroid function tests detects thyrotoxicosis (angina) or hypothyroidism (hyperlipidemia and CAD) and urea and electrolytes to evaluate renal function. High cholesterol levels or impaired glucose tolerance suggest further tests for CAD [25].

\section{Non-invasive tests}

\section{Exercise test}

Exercise test is a common non-invasive method used to assess a patient's overall exercise capacity, exertional symptoms, heart rate and blood pressure response to exercise [25]. It is useful for detecting inducible ischemia by increasing myocardial oxygen demand. The test provokes cardiac ischemia by increasing myocardial activity and oxygen demand. Exercise tests adopts the principles proposed in the ischemia cascade (Figure 2).

The cascade suggests increasing severity and duration of ischemia induces sequential changes in coronary perfusion, relaxation/ contraction, wall motion, repolarization and ultimately symptoms detectable by cardiac testing modalities [60]. However, the production of ischemia depends extent of the exercise and flow disturbance (coronary stenosis $<70 \%$ may not be detectable by exercise testing) [50].

\section{Myocardial perfusion imaging}

Myocardial Perfusion Imaging (MPI) visualizes coronary perfusion revealing myocardial areas with inadequate perfusion. Two extensively validated techniques are single photon emission computed tomography (SPECT) and positron emission tomography (PET). Reversible perfusion deficits indicate ischemia while fixed perfusion deficits indicate infarction or attenuation by underlying myocardial tissue [25]. Novel cardiovascular imaging modalities may allow for detecting myocardial viability, beneficial for planning for vascularization [61].

\section{Coronary calcification score}

Coronary calcification is a risk factor for $\mathrm{CAD}$ and a poor prognostic marker. Fast electron-beam computed tomography (CT) scanning allows for non-invasive quantification of coronary calcification. It has better accuracy compared to the older technique of fluoroscopy for detecting coronary calcification [25].

\section{Stress echocardiography}

Same to exercise testing, stress echocardiography is a non-invasive test for detecting inducible ischemia based on the principles of ischemia cascade (Figure 2) [60]. Stress Echo visualizes changes in regional wall motion and overall left ventricular function under stressful conditions such as exercise or pharmacological stress. The modality is also able to visualize dynamic LV outflow tract gradient in HCM and ischemic papillary muscle dysfunction underlying mitral regurgitation [25].

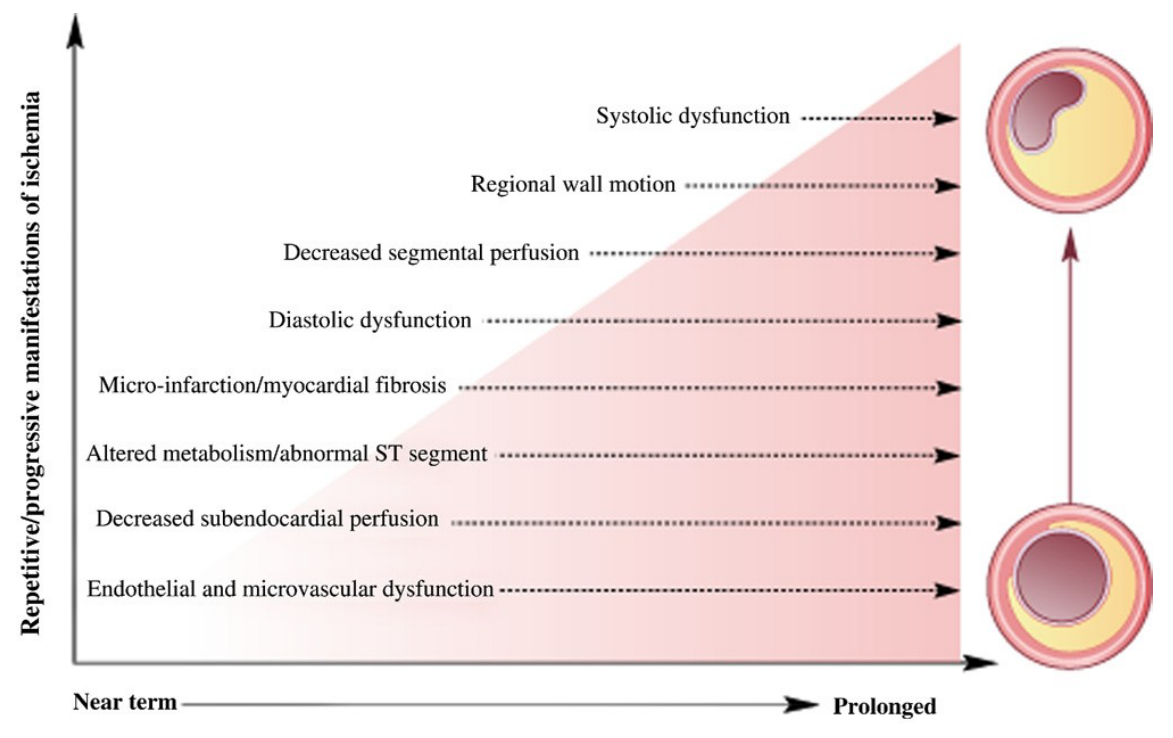

Exposure time of mismatch in myocardial oxygen supply/demand

Figure 2. Ischemia Cascade [60]

Repetitive or progressive manifestation of ischemia. Begins with endothelial and microvascular dysfunction, decreased sub-endocardial perfusion, alterations in metabolic/ST segment elevation, micro infarct, diastolic dysfunction and finally systolic dysfunction. 


\section{Cardiac magnetic resonance imaging}

Cardiac Magnetic Resonance Imaging (CMRI) is a non-invasive imaging modality for detecting coronary stenosis as well as providing prognostic information [25,62]. It is useful for visualizing the extent and severity of CAD in patients having clinical symptoms and results of non-invasive testing (excluding stress testing) to detect ICM [61]. CMRI can evaluate acute and chronic CAD. Because of its high spatial resolution, it is considered a reference standard for the assessment of global and regional myocardial dysfunction and quantification of myocardial infarction [22]. Although coronary angiography remains the mainstay method of assessment of the severity of CAD, its main limitation is its reliance on comparison to adjacent non-diseased reference segments to assess degree of stenosis and thus the lack of a normal reference segment in diffuse CAD may lead to underestimation or significant inter-observer variability [63-66]. In addition to detecting CAD, Cardiac MRI has been shown to have high specificity and sensitivity in visualizing and distinguishing viable from non-viable myocardium.

\section{Meta-analysis of cmri assessment of myocardial viability}

The search for studies on cardiac magnetic resonance imaging (CMRI) as a diagnosis method for ICM included online databases and Google Scholar with MeSH terms and key words including cardiac magnetic resonance imaging, ischemic cardiomyopathy, ischemic heart disease, coronary artery disease with LV dysfunction and myocardial viability. The search was limited to published studies systematically evaluating patients; thus, excluding case reports and studies that assessed a few patients. Citation tracking in review studies was done to discover additional studies that were not included in the results of online search. Data abstracted included first author and year, study size (sample), mean age in years, modality, gender (male \%), number of segments, sensitivity, specificity and conclusion (Table 4 ).

Table 4. Summary of Studies on Diagnosis of Ischemic Cardiomyopathy

\begin{tabular}{|c|c|c|c|c|c|c|c|c|c|}
\hline 1st Author [Ref.\#] & Year & Study Size & Mean Age & Modality & Male (\%) & Segments & Sensitivity (\%) & Specificity (\%) & Conclusion \\
\hline Baer et al. [67] & 1995 & 35 & 59 & $\begin{array}{l}\text { FDG-PET/ DS CMR } \\
\text { Phillips } 1.5 \mathrm{~T}\end{array}$ & 100 & 2200 & 88 & 87 & $\begin{array}{l}\text { Preserved end-diastolic wall } \\
\text { thickness and a Dobutamine- } \\
\text { inducible contraction reserve } \\
\text { improve MRI sensitivity in detecting } \\
\text { viable myocardium }\end{array}$ \\
\hline $\begin{array}{l}\text { Lauerma et al. } \\
{[68]}\end{array}$ & 2000 & 10 & 69 & DS CMR, Siemens $1.5 \mathrm{~T}$ & 80 & -- & 79 & 93 & $\begin{array}{l}\text { Dobutamine MRI has high } \\
\text { specificity in detecting unviable } \\
\text { myocardium. }\end{array}$ \\
\hline Klein et al. [69] & 2002 & 31 & 59 & $\begin{array}{l}\text { PET/ LGE-MRI Phillips } \\
1.5 \mathrm{~T}\end{array}$ & 84 & 1023 & 86 & 94 & $\begin{array}{l}\text { MRI hyper-enhancement detects } \\
\text { location and extent of non-viable } \\
\text { myocardium }\end{array}$ \\
\hline Perin et al. [70] & 2002 & 15 & 62 & LGE-MRI, Phillips $1.5 \mathrm{~T}$ & 67 & 275 & 93 & 88 & $\begin{array}{l}\text { LGE-MRI distinguishes normal } \\
\text { myocardium from sub-endocardial } \\
\text { and transmural infarcts }\end{array}$ \\
\hline Hunold et al. [71] & 2002 & 29 & -- & $\begin{array}{l}\text { LGE-MRI, Siemens } \\
1.5 \mathrm{~T}\end{array}$ & -- & 1753 & 84 & 76 & $\begin{array}{l}\text { LGE-MRI has a close agreement in } \\
\text { detecting transmural scars compared } \\
\text { to PET }\end{array}$ \\
\hline Wang et al. [72] & 2006 & 20 & -- & LGE-MRI. SPECT & -- & 221 & 92 & 93 & $\begin{array}{l}\text { LGE-MRI allows assessment of } \\
\text { myocardial viability in chronic } \\
\text { ischemic heart disease }\end{array}$ \\
\hline Zhang et al. [73] & 2005 & 47 & 60 & $\begin{array}{l}\text { LGE-MRI/ Doppler } \\
\text { Echo SRI }\end{array}$ & 76 & 99 & 91 & 96 & $\begin{array}{l}\text { LGE-MRI can detected location and } \\
\text { extent of transmural scar after MI }\end{array}$ \\
\hline $\begin{array}{l}\text { Motoyasu et al. } \\
\text { [74] }\end{array}$ & 2003 & 23 & 63 & $\begin{array}{l}\text { Dobutamine Cine MRI, } \\
\text { Philips } 1.5 \mathrm{~T}\end{array}$ & 87 & 1380 & 89 & 80 & $\begin{array}{l}\text { Dobutamine MRI has superior } \\
\text { detection of myocardial viability } \\
\text { than LGE-MRI (sensitivity } 83 \text {, } \\
\text { specificity } 71 \% \text { ) }\end{array}$ \\
\hline $\begin{array}{l}\text { Yoshinaga et al. } \\
{[75]}\end{array}$ & 2001 & 23 & 67 & $\begin{array}{l}\text { DSE/ DS SPECT, } \\
\text { Siemens } 1.5 \mathrm{~T}\end{array}$ & 76 & 294 & 78 & 94 & $\begin{array}{l}\text { DSE and DS SPECT (Sensitivity } \\
76 \% \text {, specificity } 100 \% \text { ) correlates } \\
\text { well in assessment of myocardia } \\
\text { viability. }\end{array}$ \\
\hline Bree et al. [76] & 2006 & 14 & 61 & DS-MRI, Siemens $1.5 \mathrm{~T}$ & -- & 84 & 91 & 78 & $\begin{array}{l}\text { DS-MRI has is a promising modality } \\
\text { for discriminating viable/non-viable } \\
\text { myocardium }\end{array}$ \\
\hline $\begin{array}{l}\text { Hundley et al. } \\
\text { [77] }\end{array}$ & 1999 & 153 & -- & $\begin{array}{l}\text { Cine CMRI, } 1.5 \mathrm{~T} \\
\text { System }\end{array}$ & 56 & -- & 83 & 83 & $\begin{array}{l}\text { Cine CMRI is a promising modality } \\
\text { to diagnose inducible ischemic for } \\
\text { patients contradicted for stress Echo. }\end{array}$ \\
\hline Nagel et al. [78] & 1999 & 208 & 60 & DS-MRI, Philips $1.5 \mathrm{~T}$ & 71 & -- & 86 & 86 & $\begin{array}{l}\text { DS-MTI achieves higher diagnostic } \\
\text { accuracy compared to DS-Echo }\end{array}$ \\
\hline $\begin{array}{l}\text { Schwitter et al. } \\
\text { [79] }\end{array}$ & 2001 & 48 & 61 & $\begin{array}{l}\text { CMRI/ PET, } 1.5 \mathrm{~T} \\
\text { System }\end{array}$ & 71 & -- & 91 & 94 & $\begin{array}{l}\text { CMRI detected significant coronary } \\
\text { stenosis and compromised } \\
\text { myocardium. }\end{array}$ \\
\hline Nagel et al. [80] & 2003 & 90 & 64 & CMRI Philips $1.5 \mathrm{~T}$ & 81 & -- & 88 & 90 & $\begin{array}{l}\text { CMRI has a high diagnostic } \\
\text { accuracy for CAD }\end{array}$ \\
\hline $\begin{array}{l}\text { Abdelrahman et } \\
\text { al. [81] }\end{array}$ & 2016 & 33 & 54 & $\begin{array}{l}\text { CMRI, Philips 3T/ } \\
\text { SPECT }\end{array}$ & 0 & 88 & -- & -- & $\begin{array}{l}\text { 3T CMRI is detects more segments } \\
\text { non-viable that SPECT. }\end{array}$ \\
\hline Nishida et al. [82] & 2005 & 83 & 68 & Multi-detector CT & 66 & -- & 65 & 63 & $\begin{array}{l}\text { Multidetector CT has high } \\
\text { specificity and negative predictive } \\
\text { value for CAC }\end{array}$ \\
\hline
\end{tabular}

CMRI: Cardiac Magnetic Resonance Imaging; SRI: Strain Rate Imaging; DSE: Dobutamine Stress Echo; DS: Dobutamine Stress; CAC: Coronary Artery Calcification 


\section{Study characteristics}

Sixteen (16) studies published between 1995 and 2016 met the inclusion criteria and were included in this meta-analysis [67-82]. The total study sample was 862 patients diagnosed with ICM $($ Mean $=62$ years; male $70 \%$ ) generating a total of 7,417 myocardial segments that were assessed. The studies demonstrate the current ICM diagnostic methods have a high specificity (Mean $=86 \%)$ and sensitivity (Mean $=$ $86 \%)$. Most of the studies assessed more than one diagnostic modality but the most common was myocardial perfusion - SPECT or PET assessed by nine $(56 \%)$ of the studies $[67,69-73,75,79,81]$ followed by late gadolinium enhancement (LGE) cardiac MRI (LGE-MRI) assessed by $31 \%$ of the studies [69-73]. Two studies, $12 \%$ examined multidetector CT [82] and the other assessed Doppler echocardiography [73]. Pharmacologic stress testing in CMRI using Dobutamine was common in $38 \%$ of the studies [67,68,74,75,76,78]. All CMRI studies used 1.5T Philips or Siemens except one [81] that used Philips 3T.

\section{Study outcomes}

Imaging modalities, CMRI in specific, have an important clinical use in the diagnosis of ICM. Compared to myocardial perfusion considered the gold standard in the detection of hibernating myocardium, CMRI has been shown to have a high diagnostic accuracy in visualizing significant coronary stenosis and viable and non-viable myocardium [78-80]. CMRI using 3T is able to detect more non-viable segments comrade to SPECT [81]. Using LGE, CMRI is able to detect the location and extent of transmural scars, and distinguish normal myocardium from sub-endocardial and transmural infarcts [69,70,72,73] with close agreement to PET [71]. Dobutamine (a pharmacologic stressor inducing ischemia) improves CMRI sensitivity in detecting viable myocardium [67] correlating with that of DS SPECT [75] and higher diagnostic accuracy compared to DS-echocardiography $[77,78]$. Dobutamine also improves CMRI detection and discrimination of viable from non-viable myocardium [76]. Multi-detector CT has also been shown to have a high specificity and negative predictive value for coronary artery calcification important in the quantification of coronary artery plaque [82].

\section{Discussion}

The 2012 ACCF/AHA practice guidelines recommend the diagnosis of ICM should involve multiple tests, both clinical examination and non-invasive imaging [50]. However, since the primary etiology of ICM is coronary artery disease, the cornerstone of diagnosis is the detection of coronary stenosis complemented by the detection of hibernating myocardium, defined as the improvement of cardiac contraction after revascularization [48]. Non-invasive imaging modalities thus are the mainstay of the diagnosis of ICM used for characterizing LV dysfunction as well as quantifying coronary stenosis as the candidate etiology [49]. Consistent with these reports, the present findings demonstrate that non-invasive imaging methods - echocardiography, cardiac MRI and cardiac CT - have a high mean diagnostic specificity and sensitivity each of $86 \%$ in the detection of ICM. The most common imaging modality was SPECT/PET echocardiography assessed by $56 \%$ of the included studies, which has been considered the gold standard in the detection of hibernating myocardium $[67,69-73,75,79,81]$. The clinical value of myocardial perfusion imaging (SPECT or PET) have been supported by the 2014 ACC/AHA/AATS/PCNA/SCAI/STS focused update of the guideline for the diagnosis and management of patients with stable ischemic heart disease. The guidelines report myocardial perfusion imaging is able to visualize coronary perfusion revealing myocardial areas with inadequate perfusion [61].
Besides SPECT/PET, cardiac MRI specifically late gadolinium enhancement (LGE-MRI) is another frequently used imaging modality for the diagnosis of ICM assessed by $31 \%$ of the included studies. LGE-MRI demonstrates a high diagnostic accuracy in the detection of significant coronary stenosis as well as both normal and hibernating myocardium comparable to SPECT [78-80]. Its high spatial resolution makes cardiac MRI a gold standard in the assessment of both global and regional myocardial dysfunction [22]. Cardiac MRI is also able to assess both acute and chronic coronary artery disease. When using Dobutamine, LGE-MRI is able to detect the location and extent of transmural scars and distinguish healthy myocardium from subendocardial and transmural infarcts. Whereas cardiac CT is of limited value to the diagnosis of ICM used by $12 \%$ of the included studies, it is clinically valuable because of its high negative predictive value for the detection of coronary artery calcification and thus essential in the quantification of coronary artery plaque [82]. Consistent with this finding, Davies [25] reports that fast electron-bean cardiac CT is important in the diagnosis of ICM by quantifying coronary calcification, which is both an important risk factor and a predictor of an ominous prognosis.

In summary, the diagnosis of ICM primarily depends on the quantification of coronary artery and the detection of hibernating myocardium. Non-invasive imaging, especially myocardial perfusion imaging modalities (SPECT/PET), is the most common imaging modality for detection of hibernating myocardium by defining coronary perfusion and subsequent detection of myocardium regions with in adequate perfusion. Cardiac MRI is also useful for detection of the location and extent of coronary stenosis as well as viable (healthy) and non-viable myocardium. Cardiac CT on the other hand is important in quantification of coronary calcification, which is an important pathophysiologic feature of developing ICM.

\section{Clinical management}

Clinical management of ICM is similar to that of non-ischemic cardiomyopathy. The main management approaches are lifestyle changes, medication and device-related therapies, and others such as revascularization and novel therapies under investigation such as autologous myoblast transplantation.

\section{Lifestyle changes}

Long-term lifestyle changes (habits) are usually recommended to manage CAD and lower the risk of complications. Important lifestyle changes include a healthy diet that is low on saturated fats, cholesterol and sodium. Other recommended changes are avoiding sedentary lifestyle, quitting smoking, and limiting or quitting alcohol [20].

\section{Medication therapy}

The ACCF/AHA task force on practice guidelines recommend medical therapy for heart failure in the setting of systolic dysfunction. Unless a contraindication is present, the ACCF/AHA guidelines recommend administration of Angiotensin Converting Enzyme (ACE) Inhibitor and/or beta-blocker to all patients to slow down the progression of heart failure and improve survival [83]. The effect of a dual therapy of ACE-inhibitors and beta-blocker is additive. Angiotensin II receptor blockers (ARBs) could be given as an alternative to ACEinhibitor for intolerant patients or an addition to ACE-inhibitor in persistently symptomatic patients with a reduced LV ejection fraction. Loop diuretics and a diet of salt restriction may be recommended to correct fluid overload [84]. Medication with adverse effects on heart failure secondary to systolic dysfunction such as non-steroidal anti- 
inflammatory medication, some antiarrhythmic medication and nondihydropyridine calcium channel blockers [47].

\section{Device therapy}

Device therapy such as cardioverter-defibrillator (ICD) and cardiac resynchronization therapy (CRT) is indicated for patients who are refractory to medication therapy. ICD therapy is recommended as either primary or secondary prevention therapy for sudden cardiac death. CRT with bi-ventricular pacing has been shown to have favorable prognosis and improves survival in patients in sinus rhythm with LV ejection fraction $\leq 35 \%$ and moderate to severe symptoms [47].

\section{Revascularization therapy}

Revascularization therapy aims to restore coronary perfusion in the setting of ischemia. It is achieved surgically through either coronary artery bypass grafting (CABG) or percutaneous coronary intervention (PCI). Revascularization has been reported to improve LV function in $20-50 \%$ of patients diagnosed with chronic LV dysfunction with significant amounts of viable myocardium [11,85-89]. Some studies report revascularization therapy achieves superior survival rates and improvement in LV function than medication therapy [9].

The 2009 ACCF/AHA guidelines on CABG recommends the therapy to patients with LV dysfunction with significant left main disease or equivalent disease ( $>70 \%$ stenosis of proximal LAD) or LAD with 2-3 vessel disease [90]. Patients having LVEF $\leq 35 \%$ and CAD amenable to CABG should receive an initial medication therapy alone instead of a dual therapy of medication and CABG [47]. Presence of heart failure in patents who have undergone coronary revascularization using PCI with stenting suggests worsening prognosis. However, with enhancements in stenting and antiplatelet therapy, clinical outcomes for PCI continues to improve [91].

\section{Autologous myoblast transplantation}

Autologous myoblast transplantation has been suggested as a viable therapy for ICM patients. The therapy is safe, feasible and could have chronic improvement in LV function in ICM patients with end-stage heart failure [92] but the large-scale Myoblast Autologous Grafting in Ischemic Cardiomyopathy (MAGIC) Trial finds no improvement in cardiac function [93]. However, data on autologous grafting is conflicting and experimental warranting further large-scale studies for validation [47].

\section{Cardiac transplantation}

Ischemic cardiomyopathy is one of the most common indications for cardiac transplantation [94]. About 10\% of ICM patients referred for cardiac transplantation have hibernating myocardium that contributes to severe LV systolic dysfunction [95-97]. Although CABG is highly recommended to these patients as an alternative chronic treatment for cardiac transplantation $[98,99]$, patients with end-stage ICM with no evidence of viability do not benefit from revascularization. [100].

\section{Meta-analysis of clinical management}

\section{Search strategy}

The present meta-analysis combines current research findings on clinical management of ischemic cardiomyopathy to determine the most frequent methods and the most common theraupteic targets. Studies for inclusion in the meta-analysis were searched in online databases PubMed, EMBASE, MEDLINE and Google Scholar using a combination of key words: ischemic cardiomyopathy, ischemic heart disease, therapies and clinical management or treatment. The studies were limited to cardiomyopathy due to ischemia and excluded case report and case series. Additional studies not found on online searches were discovered from screening reference lists of selected studies and review studies. Data abstracted from the included studies included author, year, clinical management methods, survival rates or mortality rates (Table 5).

\section{Study characteristics}

Thirteen (13) studies conducted between 1983 and 2013 meeting the inclusion criteria were included in this meta-analysis. The total sample of patients evaluated in the 13 studies was 6,305, with mean age $=60$ years and $60 \%$ male ( $40 \%$ female) with a mean follow-up of 62 months. About half of the studies (54\%) evaluated more than one clinical management methods of ICM [103,104,106-110]. The most studied clinical management approach in $56 \%$ of the studies was revascularization through coronary artery graft by-pass (CABG) alone or with medication [9,102-109]. Three other studies [19\%] assessed cardiac transplantation $[94,99,101]$.

\section{Study outcomes}

The studies demonstrate coronary revascularization, medical therapy and cardiac transplantation improve 5-year survival rate of ICM patients $(66 \%)$ and have preventive effect against cardiac death indicated by a low mortality rate (19\%). Although cardiac transplantation has favorable long-term outcomes, limited donor availability and long wait-times has influenced a vigorous search for alternative therapies such as coronary revascularization using CABG [94]. However, cardiac transplantation is usually indicated for ICM patients with end stage ICM and having no viable or hibernating myocardium. For ICM patients with viable myocardium, CABG provides extended event free and survival benefits compared to medication alone in ICM patients with LV dysfunction [109].

\section{Discussion}

In the present meta-analysis, clinical management of ICM targets to relieve symptoms and slow down the progression of heart failure. The common methods used were coronary revascularization therapy (coronary artery bypass graft surgery), medical therapy and cardiac transplantation, which convey a protective effect against cardiac death (19\%) and significantly improved 5-year survival rates at a mean of $66 \%$. Coronary artery bypass graft (CABG) surgery, either alone or concomitant with medical therapy, was the most common treatment approach used in the 13 studies. For ICM patients with viable myocardium, CABG had clinically superior beneficial effects evident in event-free survival compared to medical therapy alone. Several previous studies [85-89] have already demonstrated that CABG improved LV function in up to $50 \%$ of ICM patients with LV dysfunction and significant viable myocardium. In a comparison study of CABG and medical therapy, Velazquez et al. [9] also reported ICM patients under CABG therapy had superior improvement in LV function and survival rates than medications alone. The present findings are also consistent with the 2009 ACCF/AHA guidelines recommending the use of CABG for ICM patients with LV dysfunction and > 70\% stenosis on left atria diameter. However, Fang and Aranki [47] proposes that ICM patients with significantly depressed LV function (LVEF $\leq 30 \%$ ) and viable myocardium should initially receive medical therapy alone instead of a dual therapy of CABG and medication. 
Table 5. Summary of Studies on Clinical Management Approaches to ICM

\begin{tabular}{|c|c|c|c|c|c|c|c|c|}
\hline 1st Author [Ref. \#] & Study Period & $\begin{array}{l}\text { Sample } \\
\text { Size }\end{array}$ & Male (\%) & Mean Age & Clinical Management Approach & $\begin{array}{l}\text { Median Follow-up } \\
\text { (Months) }\end{array}$ & $\begin{array}{l}\text { 5-yr Survival Rate } \\
(\%)\end{array}$ & Mortality (\%) \\
\hline Aziz [94] & $1987-1998$ & 133 & -- & 51 & Cardiac Transplantation & 87 & 62 & 11.2 \\
\hline Kron et al. [99] & 1983-1988 & 39 & 79 & 63 & Cardiac Transplantation & 21 & $83 *$ & 19.0 \\
\hline Guddeti [101] & 2006-2011 & 46 & 40 & 60 & Cardiac Transplantation & 88 & $50^{*}$ & 4.0 \\
\hline Velazquez et al. [9] & $2002-2007$ & 610 & 27 & 60 & CABG + Medication & 56 & -- & 36.0 \\
\hline Velazquez et al. [102] & $2002-2007$ & 610 & 27 & 60 & CABG + Medication & 117 & -- & 41.0 \\
\hline \multirow{3}{*}{ Ribeiro et al. [103] } & \multirow{3}{*}{ 2006- } & 35 & 21 & 65 & CABG (viable anterior wall) & 24 & -- & 2.8 \\
\hline & & 39 & 24 & 16 & CABG + VR (viable) & 24 & -- & 4.7 \\
\hline & & 63 & 27 & 63 & CABG + VR (non-viable) & 24 & -- & 5.1 \\
\hline \multirow{2}{*}{ Maltais et al. [104] } & 1993-2009 & 55 & 76 & 70 & CABG & 50 & 71 & 22.0 \\
\hline & 2007-2011 & 33 & 85 & 71 & LAD & 50 & 94 & 15.0 \\
\hline Chen et al. [105] & $1999-2005$ & 212 & 73 & 64 & CABG & 32 & 49 & 7.0 \\
\hline \multirow{2}{*}{ O'Connor [106] } & \multirow{2}{*}{ 1969-1994 } & 343 & 73 & 63 & CABG & 120 & 61 & -- \\
\hline & & 1068 & 72 & 62 & Medication & 120 & 37 & -- \\
\hline \multirow{2}{*}{ Tyras et al. [107] } & \multirow{2}{*}{ 1970-1979 } & 89 & 86 & 52 & CABG & 52 & 64 & 12.4 \\
\hline & & 107 & 92 & 56 & CABG + Medication & 52 & 89 & 3.7 \\
\hline \multirow{2}{*}{ Kwon et al. [108] } & \multirow{2}{*}{$2002-2006$} & 245 & 78 & 63 & CABG & 69 & -- & 37.0 \\
\hline & & 205 & 71 & 63 & Medication & 69 & -- & 47.0 \\
\hline \multirow{2}{*}{ Carson et al. [109] } & \multirow{2}{*}{2013} & 610 & -- & 59 & CABG + Medication & 56 & -- & 35.7 \\
\hline & & 602 & -- & 59 & Medication & 56 & -- & 40.5 \\
\hline Menicanti et al. [110] & $1998-2005$ & 1161 & 62 & 83 & Surgical VR & 56 & 63 & $4.9^{* *}$ \\
\hline
\end{tabular}

*10-year Survival Rate; **30-day Morality Rate; VR: Ventricular Reconstruction; CABG: Coronary Artery Bypass Graft; LAD: Left Ventricular Assist Devices

Cardiac transplantation is another common clinical management approach for treating ICM patients assessed by $23 \%$ of the included studies. It provides ICM patients with the highest chronic (10-year) survival rate of up to $83 \%$ [99] and lower mortality rates of between $4 \%$ [101] and 19\% [99]. In a ten-year study of ICM, Aziz et al. [94] support the present findings, reporting that ICM is among the most common indication for cardiac transplantation. Although CABG is initially indicated for ICM patients with LV dysfunction and severely depressed LV dysfunction, cardiac transplantation may be considered as an alternative therapy. Further, Mac Iver et al. [100] report that for ICM patients with end-stage heart failure and those who do not exhibit any clinical benefit from cardiac revascularization are usually considered for cardiac transplantation. In summary, the main therapeutic target for clinical management of ICM is relieving symptoms and preventing the progression of heart failure. Medical therapy is the initial therapy while cardiac revascularization is considered for those with LV dysfunction and severe LV dysfunction. Cardiac transplantation is considered for ICM patients with end-stage heart failure or refractory to a dual therapy of CABG and medication.

\section{Conclusion}

The current systems of classification of cardiomyopathies based on morphological and functional characteristics of the myocardium exclude cardiomyopathies secondary to ischemia. However, ischemic cardiomyopathy is a well-recognized disease entity, re-igniting the debate for the need of etiologic-based classification. ICM causes an imbalance between myocardial oxygen demand and supply leading to myocyte loss, myocardial scarring and ventricular failure. The prevalence of ICM is not completely understood mainly because of the lack of a standardized and universally acceptable terminology. Current studies variously refer to ICM as ischemic heart disease or its three leading non-fatal sequela (angina pectoris, acute myocardial infarction and ischemic heart failure). The main risk factors for ICM are poor nutrition, sedentary lifestyle, chronic use of tobacco, advance age, serum lipids and obesity. The most common reasons for visit to the clinic are exertional dyspnea, peripheral edema, fatigue, persistent coughing, pulmonary congestion, palpitations, weight gain and loss of appetite. Its clinical spectrum includes angina pectoris, acute myocardial infarction, instable angina and ischemic heart failure all occurring in the setting of myocardial ischemia. Prognostic predictors are severely depressed LV systolic function, age of the patient, capacity to exercise and co-morbidities. The main etiopathogenesis mechanisms include acute changes in coronary plaque, inflammation, coronary thrombosis and vascular remodeling. Diagnosis is two-step: first to detect CAD based on angiographic findings and second to use non-invasive imaging (SPECT/PET, cardiac MRI or cardiac CT) to determine the presence, location and amount of viable myocardium. Clinical management methods are lifestyle modifications, medical therapy, device therapy (ICD or cardiac resynchronization therapy), revascularization and cardiac transplantation.

\section{References}

1. Brigden W (1957) Uncommon myocardial diseases: the non-coronary cardiomyopathies The Lancet 270: 1243-1249. [Crossref]

2. Brandenburg RO, Chazov E, Cherian G, Falase AO, et al. (1981). Report of the WHO ISFC task force on definition and classification of cardiomyopathies. Circulation 64: 437A-438A.

3. Richardson P, McKenna W, Bristow M, Maisch B, Mautner B, et al. (1996). Report of the 1995 World Health Organization/International Society and Federation of Cardiology Task Force on the definition and classification of cardiomyopathies. Circulation 93: 841-842. [Crossref]

4. Raftery EB, Banks DC, Oram S. (1969). Occlusive disease of the coronary arteries presenting as primary congestive cardiomyopathy. The Lancet 294: 1147-1150. [Crossref]

5. Cheng TO (2002) Ischemic cardiomyopathy: a historical note. J Am Coll Cardiol 39 1564-1565. [Crossref]

6. Burch GE, Giles TD, Colcolough HL (1970). Ischemic cardiomyopathy. American Heart Journal 79: 291-292.

7. Felker GM, Shaw LK, O'Connor CM (2002). A standardized definition of ischemic cardiomyopathy for use in clinical research. J Am Coll Cardiol 39: 210-218. [Crossref]

8. Anversa P, Sonnenblick EH (1990). Ischemic cardiomyopathy: Pathophysiologic mechanisms. Progress in Cardiovascular Diseases 33: 49-70. 
9. Velazquez EJ, Lee KL, Deja MA, Jain A, Sopko G, et al. (2011) Coronary-artery bypass surgery in patients with left ventricular dysfunction. $N$ Engl J Med 364: 16071616. [Crossref]

10. Bonow RO, Maurer G, Lee KL, Holly TA, Binkley PF, et al. (2011). Myocardial viability and survival in ischemic left ventricular dysfunction. $N$ Engl J Med 364 1617-1625.

11. Allman KC, Shaw LJ, Hachamovitch R, Udelson JE (2002). Myocardial viability testing and impact of revascularization on prognosis in patients with coronary artery disease and left ventricular dysfunction: A meta-analysis. J Am Coll Cardiol 39: 11511158. [Crossref]

12. Bozkurt B, Colvin M, Cook J, Cooper LT, Deswal A, et al. (2016). Current diagnostic and treatment strategies for specific dilated cardiomyopathies: A scientific statement from the American Heart Association. Circulation 134: e579-e646. [Crossref]

13. Mathers C, Truelsen T, Begg S, Satoh T (2004). Global burden of ischemic heart disease in the year 2000. Global Burden of Disease 2000.

14. Moran AE, Forouzanfar MH, Roth GA, Mensah GA, Ezzati M, et al. (2014) The global burden of ischemic heart disease in 1990 and 2010: the Global Burden of Disease 2010 study. Circulation 129: 1493-1501. [Crossref]

15. Moran AE, Oliver JT, Mirzaie M, Forouzanfar MH, Chilov M, et al. (2012). Assessing the global burden of ischemic heart disease: part 1: methods for a systematic review of the global epidemiology of ischemic heart disease in 1990 and 2010. Global heart 7: 315-329. [Crossref]

16. Forouzanfar MH, Moran AE, Flaxman AD, Roth G, Mensah GA, et al. (2012). Assessing the global burden of ischemic heart disease: part 2: analytic methods and estimates of the global epidemiology of ischemic heart disease in 2010. Global heart 7: 331-342. [Crossref]

17. Kinch SH, Doyle JT, Hilleboe HE (1963). Risk factors in ischemic heart disease. American Journal of Public Health and the Nations Health, 53: 438-442.

18. Yarnell JW, Baker IA, Sweetnam PM, Bainton D, O'Brien JR, et al. (1991). Fibrinogen, viscosity, and white blood cell count are major risk factors for ischemic heart disease. The Caerphilly and Speedwell collaborative heart disease studies. Circulation 83: 836844. [Crossref]

19. Elwood PC (1984). Caerphilly and Speedwell Collaborative Heart-Disease Studies. $J$ Epidemiol Community Health 38: 259-262. [Crossref]

20. Morrow DA, Boden WE (2015). Stable ischemic heart disease. Braunwald's Heart Disease: A Textbook of Cardiovascular Medicine. 10th Ed. Philadelphia, PA: Elsevier Saunders.

21. Mantziari L, Ziakas A, Ventoulis I, Kamperidis V, Lilis L, et al. (2012). Differences in Clinical Presentation and Findings between Idiopathic Dilated and Ischaemic Cardiomyopathy in an Unselected Population of Heart Failure Patients. The Open Cardiovascular Medicine Journal 6, 98. [Crossref]

22. Assunção FB, de Oliveira DC, Souza VF, Nacif MS (2016). Cardiac magnetic resonance imaging and computed tomography in ischemic cardiomyopathy: An update. Radiologia Brasileira 49: 26-34. [Crossref]

23. Carvalho AC, Sousa JMA (2001). Cardiopatia isquêmica. Rev Bras Hipertens 8: 297-305.

24. Behar S, Reicher-Reiss H, Abinader E, Agmon J, Friedman Y, et al. (1992). The prognostic significance of angina pectoris preceding the occurrence of a first acute myocardial infarction in 4166 consecutive hospitalized patients. Am Heart J 123: 14811486. [Crossref]

25. Davies SW (2001). Clinical presentation and diagnosis of coronary artery disease: Stable angina. British Medical Bulletin 59: 17-27.

26. National Heart, Lung and Blood Institute. (2016). What Are the Signs and Symptoms of Coronary Heart Disease? Retrieved from https://www.nhlbi.nih.gov/health/healthtopics/topics/cad/signs

27. Davies SW, Lipkin D. (1996). Breathlessness. In Weatherall, D. J., Ledingham, J. G. G., Warrell, D. A. (Eds) Oxford Textbook of Medicine, 3rd Edn. Oxford: Oxford University Press.

28. Fallavollita JA, Heavey BM, Luisi AJ Jr, Michalek SM, Baldwa S, et al. (2014). Regional myocardial sympathetic denervation predicts the risk of sudden cardiac arrest in ischemic cardiomyopathy. J Am Coll Cardiol 63: 141-149. [Crossref]

29. Flore V, Willems R (2012). Preventing sudden cardiac death in patients with ischemic cardiomyopathy. European Cardiology Review 8: 134-138.

30. Gheorghiade M1, Bonow RO (1998) Chronic heart failure in the United States: a manifestation of coronary artery disease. Circulation 97: 282-289. [Crossref]
31. Bart BA, Shaw LK, McCants CB Jr, Fortin DF, et al. (1997). Clinical determinants of mortality in patients with angiographically diagnosed ischemic or nonischemic cardiomyopathy. J Am Coll Cardiol 30: 1002-1008. [Crossref]

32. Adams KF Jr, Dunlap SH, Sueta CA, Clarke SW, Patterson JH, et al. (1996). Relation between gender, etiology and survival in patients with symptomatic heart failure. $J \mathrm{Am}$ Coll Cardiol 28: 1781-1788. [Crossref]

33. Likoff MJ, Chandler SL, Kay HR (1987). Clinical determinants of mortality in chronic congestive heart failure secondary to idiopathic dilated or to ischemic cardiomyopathy. Am J Cardiol 59: 634-638. [Crossref]

34. Franciosa JA, Wilen M, Ziesche S, Cohn JN (1983). Survival in men with severe chronic left ventricular failure due to either coronary heart disease or idiopathic dilated cardiomyopathy. Am J Cardiol 51: 831-836. [Crossref]

35. Uretsky BF, Thygesen K, Armstrong PW, Cleland JG, Horowitz JD, et al. (2000). Acute coronary findings at autopsy in heart failure patients with sudden death. Results from the Assessment of Treatment with Lisinopril And Survival (ATLAS) trial. Circulation 102: 611-616. [Crossref]

36. Santana CA, Shaw LJ, Garcia EV, Soler-Peter M, Candell-Riera J, et al. (2004) Incremental prognostic value of left ventricular function by myocardial ECG-gated FDG PET imaging in patients with ischemic cardiomyopathy. J Nucl Cardiol 11: 542550. [Crossref]

37. Candell-Riera J, Romero-Farina G, Aguadé-Bruix S, Castell-Conesa J (2009). Ischemic cardiomyopathy: A clinical nuclear cardiology perspective. Rev Esp Cardiol 62: 903917. [Crossref]

38. Effat MA (1995) Pathophysiology of ischemic heart disease: an overview. AACN Clin Issues 6: 369-374. [Crossref]

39. Pepine CJ, Nichols, WW (2007). The pathophysiology of chronic ischemic heart disease. Clinical Cardiology 30(S1).

40. Schoen FJ (1989). Interventional and surgical cardiovascular pathology: Clinical correlations and basic principles. WB Saunders Company.

41. Schoenhagen P, Nissen SE, Tuzcu EM (2003). Coronary arterial remodeling: from bench to bedside. Current Atherosclerosis Reports 5: 150-154.

42. Kinlay S (2001). What has intravascular ultrasound taught us about plaque biology? Curr Atheroscler Rep 3: 260-266. [Crossref]

43. Glagov S, Weisenberg E, Zarins CK, Stankunavicius R, Kolettis GJ (1987) Compensatory enlargement of human atherosclerotic coronary arteries. $N$ Engl $J$ Med 316: 1371-1375.

44. Libby P, Theroux P (2005) Pathophysiology of coronary artery disease. Circulation 111 3481-3488. [Crossref]

45. Fujii K, Mintz GS, Carlier SG, Costa Jd Jr, Kimura M, et al. (2006). Intravascular ultrasound profile analysis of ruptured coronary plaques. Am J Cardiol 98: 429-435. [Crossref]

46. Briceno N, Schuster A, Lumley M, Perera D (2016). Ischaemic cardiomyopathy: pathophysiology, assessment and the role of revascularisation. Heart 102: 397-406. [Crossref]

47. Fang JC, Aranki S (2011). Diagnosis and management of ischemic cardiomyopathy UpToDate, Available at http://cursoenarm.net/UPTODATE/contents/mobipreview. $\mathrm{htm} ? 4 / 24 / 4481$ ? source $=$ see_link

48. Felker GM, Thompson RE, Hare JM, Hruban RH, Clemetson DE, et al. (2000) Underlying causes and long-term survival in patients with initially unexplained cardiomyopathy. N Engl J Med 342: 1077-1084. [Crossref]

49. McMurray JJ, Adamopoulos S, Anker SD, Auricchio A, Böhm M, et al. (2012). ESC Guidelines for the diagnosis and treatment of acute and chronic heart failure 2012. Eur $J$ Heart Fail 14(8), 803-869.

50. Fihn SD, Gardin JM, Abrams J, Berra K, Blankenship JC, et al. (2012). 2012 ACCF/ AHA/ACP/AATS/PCNA/SCAI/STS guideline for the diagnosis and management of patients with stable ischemic heart disease. J Am Coll Cardiol 60: e44-e164. [Crossref]

51. Chatterjee K (1998). Recognition and management of patients with stable angina pectoris. Primary Cardiology. Philadelphia: WB Saunders, 234-56.

52. Daly CA, De Stavola B, Sendon JL, Tavazzi L, Boersma E, et al. (2006). Predicting prognosis in stable angina: Results from the Euro heart survey of stable angina: prospective observational study. $B M J 332: 262-267$. [Crossref]

53. Daly C, Norrie J, Murdoch DL, Ford I, Dargie HJ, et al. (2003). The value of routine non-invasive tests to predict clinical outcome in stable angina. Eur Heart J 24: 532-540. 
54. Hammermeister KE, DeRouen TA, Dodge HT (1979). Variables predictive of survival in patients with coronary disease. Selection by univariate and multivariate analyses from the clinical, electrocardiographic, exercise, arteriographic, and quantitative angiographic evaluations. Circulation 59: 421-430. [Crossref]

55. Block WJ, Crumpacker EL, Dry TJ, Gage RP (1952). Prognosis of angina pectoris: observations in 6,882 cases. J Am Med Assoc 150: 259-264. [Crossref]

56. European Coronary Surgery Study Group. (1980). Prospective Randomised Study of Coronary Artery Bypass Surgery In Stable Angina Pectoris: Second Interim Report by the. The Lancet 316: 491-495. [Crossref]

57. Frank CW, Weinblatt E, Shapiro S (1973) Angina pectoris in men. Prognostic significance of selected medical factors. Circulation 47: 509-517. [Crossref]

58. Murphy ML, Hultgren HN, Detre K, Thomsen J, Takaro T. (1977). Treatment of chronic stable angina: a preliminary report of survival data of the randomized Veterans Administration Cooperative Study. N Engl J Med 297: 621-627. [Crossref]

59. Proudfit WJ, Bruschke AV, MacMillan JP, Williams GW, Sones FM Jr (1983). Fifteenyear survival study of patients with obstructive coronary artery disease. Circulation 68: 986-997. [Crossref]

60. Shaw LJ, Bugiardini R, Merz CN. (2009). Women and ischemic heart disease: evolving knowledge. J Am Coll Cardiol 54: 1561-1575. [Crossref]

61. Davies SW (2001). Fihn SD, Blankenship JC, Alexander KP, Bittl JA, Byrne JG, Fletcher BJ., ... \& Naidu SS. (2014). 2014 ACC/AHA/AATS/PCNA/SCAI/STS focused update of the guideline for the diagnosis and management of patients with stable ischemic heart disease. Circulation CIR-0000000000000095.

62. Doesch C, Papavassiliu T. (2014). Diagnosis and management of ischemic cardiomyopathy: role of cardiovascular magnetic resonance imaging. World $J$ of Cardiol 6: 1166. [Crossref]

63. Leape LL, Park RE, Bashore TM, Harrison JK, Davidson CJ, et al. (2000). Effect of variability in the interpretation of coronary angiograms on the appropriateness of use of coronary revascularization procedures. Am J Cardiol 139: 106-113. [Crossref]

64. Fleming RM, Kirkeeide RL, Smalling RW, Gould KL, Stuart, Y. (1991). Patterns in visual interpretation of coronary arteriograms as detected by quantitative coronary arteriography. J Am Coll Cardiol 18: 945-951. [Crossref]

65. Nallamothu BK, Spertus JA, Lansky AJ, Cohen DJ, Jones PG, et al. (2013). Comparison of clinical interpretation with visual assessment and quantitative coronary angiography in patients undergoing percutaneous coronary intervention in contemporary practice: the Assessing Angiography (A2) project. Circulation, CIRCULATIONAHA-113.

66. Kwong RY, Schussheim AE, Rekhraj S, Aletras AH, Geller N, et al. (2003). Detecting acute coronary syndrome in the emergency department with cardiac magnetic resonance imaging. Circulation 107: 531-537. [Crossref]

67. Baer FM, Voth E, Schneider CA, Theissen P, Schicha H, et al. (1995). Comparison of low-dose dobutamine-gradient-echo magnetic resonance imaging and positron emission tomography with $[18 \mathrm{~F}]$ fluorodeoxyglucose in patients with chronic coronary artery disease. Circulation 91: 1006-1015.

68. Lauerma K, Niemi P, Hänninen H, Janatuinen T, Voipio-Pulkki LM, et al. (2000). Multimodality MR imaging assessment of myocardial viability: combination of firstpass and late contrast enhancement to wall motion dynamics and comparison with FDG PET: Initial experience. Radiology 217: 729-736. [Crossref]

69. Klein C, Nekolla SG, Bengel FM, Momose M, Sammer A, et al. (2002). Assessment of myocardial viability with contrast-enhanced magnetic resonance imaging. Circulation 105: 162-167.

70. Perin EC, Silva GV, Sarmento-Leite R, Sousa AL, Howell M, et al. (2002). Assessing myocardial viability and infarct transmurality with left ventricular electromechanical mapping in patients with stable coronary artery disease. Circulation 106: 957-961. [Crossref]

71. Hunold P, Brandt-Mainz K, Freudenberg L, Vogt FM, Neumann T, et al. (2002). Evaluation of myocardial viability with contrast-enhanced magnetic resonance imaging--comparison of the late enhancement technique with positronemission tomography. RoFo 174: 867-873. [Crossref]

72. Wang YN, Jin ZY, Zhang ZH, Kong LY, Chen LB, et al. (2006). Assessment of myocardial viability with contrast-enhanced magnetic resonance imaging and comparison with single-photon emission computed tomography. Chin Med Sci J 21: 239-244. [Crossref]

73. Zhang Y, Chan AK, Yu CM, Yip GW, Fung JW, et al. (2005). Strain rate imaging differentiates transmural from non-transmural myocardial infarction: A validation study using delayed-enhancement magnetic resonance imaging. J Am Coll Cardiol 46: 864-871. [Crossref]
74. Motoyasu M, Sakuma H, Ichikawa Y, Ishida N, Uemura S, et al. (2003). Prediction of regional functional recovery after acute myocardial infarction with low dose dobutamine stress cine MR imaging and contrast enhanced MR imaging. J Cardiovasc Magn Reson 5: 563-574. [Crossref]

75. Yoshinaga K, Morita K, Yamada S, Komuro K, Katoh C, et al. (2001). Low-dose dobutamine electrocardiograph-gated myocardial SPECT for identifying viable myocardium: Comparison with dobutamine stress echocardiography and PET. J Nucl Med 42: 838-844. [Crossref]

76. Bree D, Wollmuth JR, Cupps BP, Krock MD, Howells A, et al. (2006). Lowdose dobutamine tissue-tagged magnetic resonance imaging with 3-dimensional strain analysis allows assessment of myocardial viability in patients with ischemic cardiomyopathy. Circulation 114: I-33. [Crossref]

77. Hundley WG, Hamilton CA, Thomas MS, Herrington DM, Salido TB, et al. (1999) Utility of fast cine magnetic resonance imaging and display for the detection of myocardial ischemia in patients not well suited for second harmonic stress echocardiography. Circulation 100: 1697-1702. [Crossref]

78. Nagel E, Lehmkuhl HB, Bocksch W, Klein C, Vogel U, et al. (1999). Noninvasive diagnosis of ischemia-induced wall motion abnormalities with the use of high-dose dobutamine stress MRI. Circulation 99: 763-770. [Crossref]

79. Schwitter J, Nanz D, Kneifel S, Bertschinger K, et al. (2001). Assessment of myocardia perfusion in coronary artery disease by magnetic resonance. Circulation 103: 2230 2235 .

80. Nagel E, Klein C, Paetsch I, Hettwer S, Schnackenburg B, et al. (2003). Magnetic resonance perfusion measurements for the noninvasive detection of coronary artery disease. Circulation 108: 432-437.

81. Abdelrahman SF, Ali MT, Salem MA, Sabri S (2016). Utility of cardiac MRI in the assessment of myocardial viability: Evaluating its role using 3-T machine in correlation with SPECT. The Egyptian Journal of Radiology and Nuclear Medicine 47: 73-81.

82. Nishida C, Okajima K, Kudo T, Yamamoto T, Hattori R, et al. (2005). The relationship between coronary artery calcification detected by non-gated multi-detector $\mathrm{CT}$ in patients with suspected ischemic heart disease and myocardial ischemia detected by thallium exercise stress testing. Ann Nucl Med 19: 647-653. [Crossref]

83. Hunt SA, Abraham WT, Chin MH, Feldman AM, Francis GS, et al. (2009). 2009 focused update incorporated into the ACC/AHA 2005 guidelines for the diagnosis and management of heart failure in adults: a report of the American College of Cardiology Foundation/American Heart Association Task Force on Practice Guidelines developed in collaboration with the International Society for Heart and Lung Transplantation. $J$ Am Coll Cardiol 53: e1-e90.

84. Cleland JG, Pennell DJ, Ray SG, Coats AJ, Macfarlane PW, et al. (2003). Myocardial viability as a determinant of the ejection fraction response to carvedilol in patients with heart failure (CHRISTMAS trial): Randomized controlled trial. The Lancet 362: 14-21. [Crossref]

85. Dreyfus GD, Duboc D, Blasco A, Vigoni F, Dubois C. (1994). Myocardial viability assessment in ischemic cardiomyopathy: benefits of coronary revascularization. Ann Thorac Surg 57: 1402-1408. [Crossref]

86. Bonow RO (1995). The hibernating myocardium: implications for management of congestive heart failure. Am J Cardiol 75: 17A-25A. [Crossref]

87. Ragosta M, Beller GA, Watson DD, Kaul S, Gimple LW (1993). Quantitative planar rest-redistribution $201 \mathrm{Tl}$ imaging in detection of myocardial viability and prediction of improvement in left ventricular function after coronary bypass surgery in patients with severely depressed left ventricular function. Circulation 87: 1630-1641. [Crossref]

88. Auerbach MA, Schöder H, Hoh C, Gambhir SS, Yaghoubi S, et al. (1999). Prevalence of myocardial viability as detected by positron emission tomography in patients with ischemic cardiomyopathy. Circulation 99: 2921-2926. [Crossref]

89. Graham MM, Ghali WA, Faris PD, Galbraith PD, Norris CM, et al. (2002). Survival after coronary revascularization in the elderly. Circulation 105: 2378-2384.

90. Eagle KA, Guyton RA, Davidoff R, Edwards FH, Ewy GA, et al. (2004). ACC/ AHA 2004 guideline update for coronary artery bypass graft surgery: a report of the American College of Cardiology/American Heart Association Task Force on Practice Guidelines (Committee to Update the 1999 Guidelines for Coronary Artery Bypass Graft Surgery). Circulation 110: e340-437. [Crossref]

91. Holper EM, Blair J, Selzer F, Detre KM, Jacobs AK, et al. (2006). The impact of ejection fraction on outcomes after percutaneous coronary intervention in patients with congestive heart failure: an analysis of the National Heart, Lung, and Blood Institute Percutaneous Transluminal Coronary Angioplasty Registry and Dynamic Registry. Am Heart J 151: 69-75. [Crossref] 
92. Dib N, Michler RE, Pagani FD, Wright S, Kereiakes DJ, et al. (2005). Safety and feasibility of autologous myoblast transplantation in patients with ischemic cardiomyopathy. Circulation 112: 1748-1755. [Crossref]

93. Menasché P, Alfieri O, Janssens S, McKenna W, Reichenspurner H, et al. (2008). The myoblast autologous grafting in ischemic cardiomyopathy (MAGIC) trial. Circulation 117: $1189-1200$

94. Aziz T, Burgess M, Rahman AN, Campbell CS, Yonan N (2001). Cardiac transplantation for cardiomyopathy and ischemic heart disease: differences in outcome up to 10 years. The Journal of Heart and Lung Transplantation 20: 525-533. [Crossref]

95. Luu M, Stevenson LW, Brunken RC, Drinkwater DM, Schelbert HR, et al. (1990). Delayed recovery of revascularized myocardium after referral for cardiac transplantation. Am Heart J 119: 668-670. [Crossref]

96. Louie HW, Laks H, Milgalter E, Drinkwater DC Jr, Hamilton MA, et al. (1991). Ischemic cardiomyopathy. Criteria for coronary revascularization and cardiac transplantation. Circulation 84(5 Suppl), III290-5. [Crossref]

97. Bortman G, Sellanes M, Odell DS, Ring WS, Olivari MT (1994). Discrepancy between pre-and post-transplant diagnosis of end-stage dilated cardiomyopathy. Am J Cardiol 74: 921-924. [Crossref]

98. Mickleborough LL, Maruyama H, Takagi Y, Mohamed S, Sun Z, et al. (1995) Results of revascularization in patients with severe left ventricular dysfunction. Circulation 92: II73-79. [Crossref]

99. Kron IL, Flanagan TL, Blackbourne LH, Schroeder RA, et al. (1989). Coronary revascularization rather than cardiac transplantation for chronic ischemic cardiomyopathy. Annals of surgery 210: 348.

100. Mac Iver RH., McGee Jr EC, McCarthy PM (2012). Cardiac Transplantation for Ischemic Heart Disease. In Coronary Artery Disease (pp. 109-123). Springer London.

101. Guddeti RR, Matsuo Y, Matsuzawa Y, Aoki T, Lennon RJ, et al. (2014). Ischemic cardiomyopathy is associated with coronary plaque progression and higher event rate in patients after cardiac transplantation. J Am Heart Assoc 3: e001091. [Crossref]
102. Velazquez EJ, Lee KL, Jones RH, Al-Khalidi HR, Hill JA, et al. (2016). Coronaryartery bypass surgery in patients with ischemic cardiomyopathy. $N$ Engl J Med 374 1511-1520.

103. Ribeiro GA, da Costa CE, Lopes MM, Albuquerque AN, Antoniali F, et al. (2006) Left ventricular reconstruction benefits patients with ischemic cardiomyopathy and non-viable myocardium. Eur J Cardiothorac Surg 29: 196-201. [Crossref]

104. Maltais S, Tchantchaleishvili V, Schaff HV, Daly RC, Suri RM, et al. (2014) Management of severe ischemic cardiomyopathy: left ventricular assist device as destination therapy versus conventional bypass and mitral valve surgery. $J$ Thorac Cardiovasc Surg 147: 1246-1250. [Crossref]

105. Chen YX, Chang Y, Tsai HW, et al. (2008). Surgical treatment for heart failure in ischemic cardiomyopathy. Acta Cardiologica Sinica 24: 92-96.

106. O'Connor CM, Velazquez EJ, Gardner LH, Smith PK, Newman MF, et al. (2002). Comparison of coronary artery bypass grafting versus medical therapy on long-term outcome in patients with ischemic cardiomyopathy (a 25-year experience from the Duke Cardiovascular Disease Databank). Am J Cardiol 90: 101-107. [Crossref]

107. Tyras DH, Kaiser GC, Barner HB, Pennington DG, Codd JE, et al. (1984). Global left ventricular impairment and myocardial revascularization: determinants of survival The Annals of Thoracic Surgery 37: 47-51. [Crossref]

108. Kwon DH, Hachamovitch R, Popovic ZB, Starling RC, Desai MY, et al. (2012). Survival in Patients With Severe Ischemic Cardiomyopathy Undergoing Revascularization Versus Medical Therapy. Circulation 126: S3-S8. [Crossref]

109. Carson P, Wertheimer J, Miller A, O'Connor CM, Pina IL, et al. (2013). The STICH trial (Surgical Treatment for Ischemic Heart Failure): mode-of-death results. JACC: Heart Failure 1: 400-408. [Crossref]

110. Menicanti L, Castelvecchio S, Ranucci M, Frigiola A, Santambrogio C, et al. (2007) Surgical therapy for ischemic heart failure: single-center experience with surgical anterior ventricular restoration. J Thorac Cardiovasc Surg 134: 433-441. [Crossref]

Copyright: (C2018 Albakri A. This is an open-access article distributed under the terms of the Creative Commons Attribution License, which permits unrestricted use, distribution, and reproduction in any medium, provided the original author and source are credited. 